\title{
Spinal Cord Diffuse Midline Glioma With Histone H3 K27M Mutation in a Pediatric Patient
}

\author{
Ran Cheng ${ }^{1+}$, Da-Peng Li ${ }^{2 \dagger}$, Nan Zhang ${ }^{3}$, Ji-Yin Zhang ${ }^{4}$, Di Zhang ${ }^{2}$, Ting-Ting Liu ${ }^{1}$, \\ Jun Yang ${ }^{5 *}$ and Ming Ge ${ }^{2 *}$
}

${ }^{1}$ Department of Emergency Surgery, National Center for Children's Health, Beijing Children's Hospital, Capital Medical University, Beijing, China, ${ }^{2}$ Department of Neurosurgery, National Center for Children's Health, Beijing Children's Hospital, Capital Medical University, Beijing, China, ${ }^{3}$ Department of Pathology, National Center for Children's Health, Beijing Children's Hospital, Capital Medical University, Beijing, China, ${ }^{4}$ Department of Otolaryngology, National Center for Children's Health, Beijing Children's Hospital, Capital Medical University, Beijing, China, ${ }^{5}$ Department of Neurosurgery, Peking University Third Hospital, Beijing, China

\section{OPEN ACCESS}

Edited by:

Chenlong Yang,

Center for Precision Neurosurgery and Oncology of Peking University Health

Science Center, China

Reviewed by:

Florian Andreas Gessler, University Hospital Rostock, Germany

Bedjan Behmanesh

Goethe University Frankfurt, Germany

*Correspondence:

Jun Yang

yangjbysy@bjmu.edu.cn

Ming Ge

gemimgbn@163.com

tThese authors have contributed equally to this work

Specialty section:

This article was submitted to Neurosurgery,

a section of the journal

Frontiers in Surgery

Received: 12 October 2020

Accepted: 20 May 2021

Published: 17 June 2021

Citation:

Cheng R, Li D-P, Zhang N, Zhang J-Y,

Zhang $D$, Liu T-T, Yang $J$ and $G e M$ (2021) Spinal Cord Diffuse Midline Glioma With Histone H3 K27M Mutation in a Pediatric Patient. Front. Surg. 8:616334. doi: 10.3389/fsurg.2021.616334
Background: Diffuse midline glioma (DMG) with histone H3 K27M mutation is a recently identified entity documented in the 2016 World Health Organization (WHO) Classification of Tumors of the Central Nervous System. Spinal cord DMGs with H3 K27M-mutant are commonly reported in adults. Herein, we reported a pediatric patient with spinal cord $\mathrm{H} 3$ K27M-mutant DMG.

Case Report: A 7-year-old girl with 1-month history of neck pain and 3-week history of progressive weakness in the right hand was presented. Spinal magnetic resonance imaging showed an intramedullary lesion with slight enhancement at the C2-7 levels. With intraoperative neuroelectrophysiological monitoring, the lesion was subtotally resected. Histopathological examination revealed a DMG with histone H3 K27M mutation corresponding to WHO grade IV. Postoperatively, the neck pain was relieved, and the upper-extremity weakness remained unchanged. Oral temozolomide was administrated for 7 months, and radiotherapy was performed for 22 courses. After an 18-month follow-up, no tumor recurrence was noted.

Conclusion: Spinal cord H3 K27M-mutant DMGs are extremely rare in pediatric patients. Preoperative differential diagnosis is challenging, and surgical resection with postoperative chemoradiotherapy may be an effective treatment.

Keywords: diffuse midline gliomas, H3K27 mutation, spinal cord tumors, pediatric neurosurgery, pathology

\section{INTRODUCTION}

H3 K27M-mutant Diffuse midline glioma (DMG) has been recognized as a distinct category in the 2016 update of the World Health Organization (WHO) Classification of Tumors of the Central Nervous System (1). This entity usually occurs in the midline of the central nervous system, and it is characterized by a specific site mutation of $\mathrm{H} 3 \mathrm{~K} 27 \mathrm{M}$. Existing evidence indicates spinal cord H3 K27M-mutant DMGs are highly malignant tumors corresponding to WHO grade IV; nevertheless, clinical manifestations, imaging features, and treatment have not yet been well-elucidated. At present, there are few reports on the diagnosis and treatment of spinal cord H3 K27M-mutant DMGs in children. Herein, we reported a pediatric patient with spinal cord H3 K27M-mutant DMG, and relevant literature was reviewed. 


\section{CASE REPORT}

A 7-year-old girl with a 1-month history of neck pain and a 3-week history of progressive weakness in the right hand was presented to us. Physical examination showed a decreased muscle strength (Grade 1/5 according to the Medical Research Council scale) in the right upper extremity, and the left and anterior movement of the neck was limited. The muscular tone was normal, and the Hoffmann's sign was negative bilaterally. Spinal magnetic resonance imaging (MRI) revealed an intramedullary lesion at the C2-7 levels. The lesion showed isointensity on T1weighted imaging and slightly hyperintensity on T2-weighted imaging; after administration of contrast medium, the lesion was heterogeneously enhanced (Figures 1A-C). A diagnosis of spinal cord glioma was suspected. The preoperative ADL (Activity of Daily Living scale) score was 65.

Microsurgical resection of the intramedullary lesion was performed with the assistance of intraoperative neuroelectrophysiological monitoring. Intraoperatively, the lesion was soft in nature and pink in color with abundant blood supply. The spinal cord was severely compressed and deformed. Eventually, a subtotal resection ( $\sim 80 \%$ of the mass) was achieved. Postoperatively, the neck pain was relieved, while the muscle strength of the right upper extremity remained unchanged
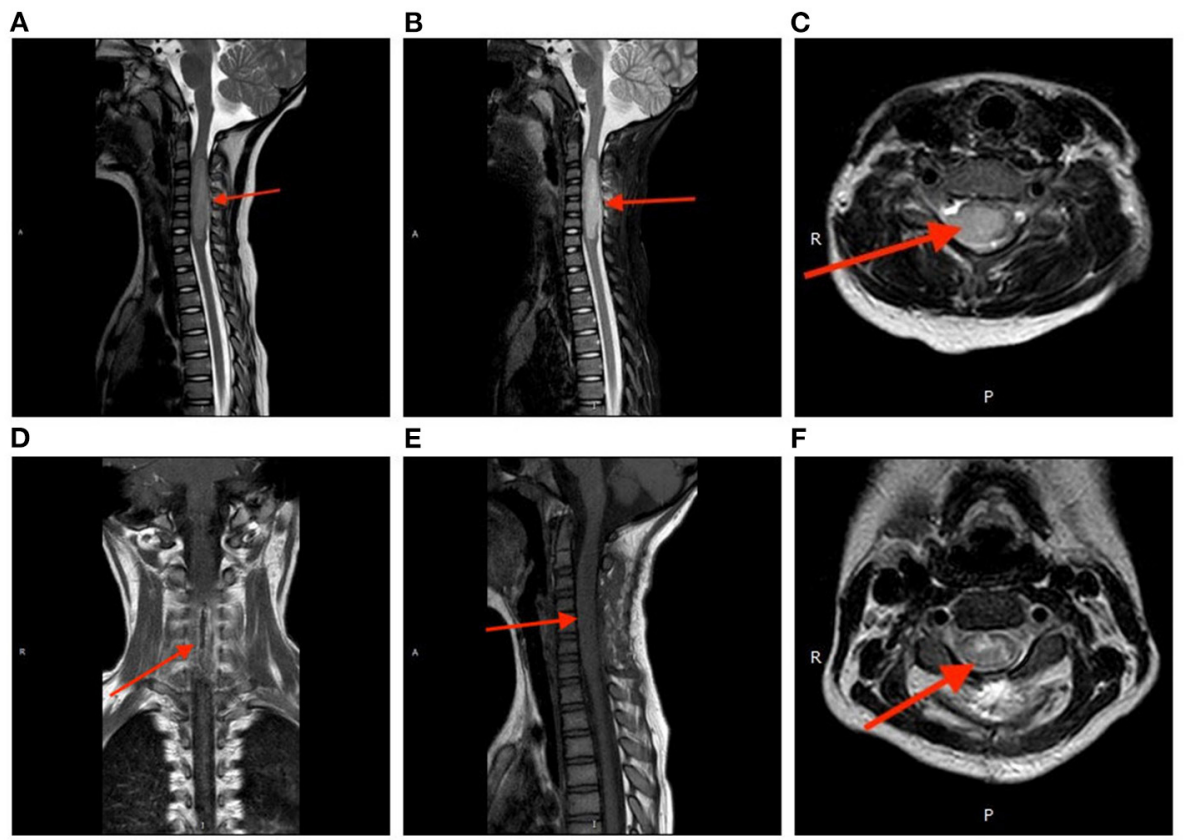

FIGURE 1 | Perioperative magnetic resonance imaging. The tumor showed isointensity on T1-weighted imaging (A) and slightly hyperintensity on T2-weighted imaging (B). After administration of contrast medium, the lesion was heterogeneously enhanced (C). Postoperative spinal MRI confirmed a subtotal resection of the tumor (D) coronal, (E) sagittal, (F) axial.

TABLE 1 | Activity of daily living scale.

\begin{tabular}{|c|c|c|c|c|c|c|c|}
\hline Item & $\begin{array}{c}\text { Complete } \\
\text { independent }\end{array}$ & $\begin{array}{l}\text { Need some } \\
\text { help }\end{array}$ & $\begin{array}{c}\text { Needs a } \\
\text { lot of } \\
\text { help }\end{array}$ & $\begin{array}{l}\text { Complete } \\
\text { dependent }\end{array}$ & Admission & Discharge & Follow-up \\
\hline Eating & 10 & 5 & 0 & - & 5 & 5 & 5 \\
\hline Washing & 5 & 0 & - & - & 0 & 0 & 3 \\
\hline Modification & 5 & 0 & - & - & 0 & 0 & 2 \\
\hline Dressing & 10 & 5 & 0 & - & 5 & 0 & 2 \\
\hline Stool control & 10 & 5 & 0 & - & 10 & 10 & 10 \\
\hline Urine control & 10 & 5 & 0 & - & 10 & 10 & 10 \\
\hline Going to the toilet & 10 & 5 & 0 & - & 5 & 0 & 5 \\
\hline Bed chair movement & 15 & 10 & 5 & 0 & 5 & 0 & 10 \\
\hline Walking on the ground & 15 & 10 & 5 & 0 & 15 & 0 & 15 \\
\hline \multirow[t]{2}{*}{ Up and down stairs } & 10 & 5 & 0 & - & 10 & 0 & 10 \\
\hline & & & & & 65 & 25 & 72 \\
\hline
\end{tabular}


(Grade 1/5); the muscle strength of the right lower extremity was Grade 2/5. The postoperative ADL score was 25 (Table 1).

Postoperative spinal MRI confirmed a subtotal resection of the tumor (Figures 1D-F). Pathological examination revealed that the density of tumor cells was moderate, the nucleus was irregular and slightly to moderately heteromorphic, and no karyokinesis was observed (Figure 2A). Immunohistochemistry showed the tumor harbored an H3 K27M mutation (Figure 2B). The Ki67 proliferation index was about $30 \%$. These characteristics conformed to a diagnosis of spinal cord H3 K27M-mutant DMG (WHO Grade IV).

Postoperatively, the girl was treated with concurrent chemoradiotherapy. Oral temozolomide was administered for 7 -months $(67 \mathrm{mg} /$ day for 42 days; thereafter, $150 \mathrm{mg} /$ day for 5 days during each 28-day cycle). In addition, 22 courses of radiotherapy (local radiotherapy: three-dimensional conformal

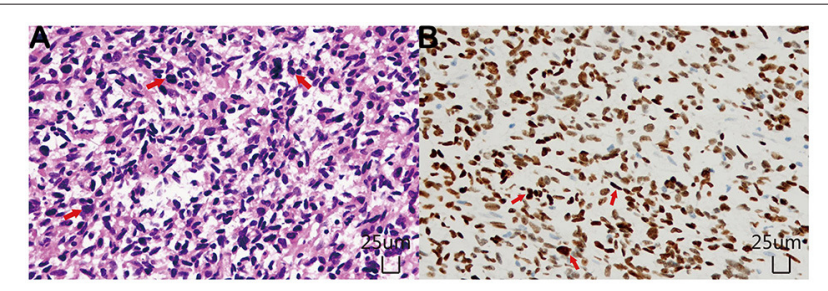

FIGURE 2 | Histopathological examinations. (A) Hematoxylin and Eosin staining ( $\times 200$ ) showed diffusely distributed tumor cells with unobvious atypia and no karyokinesis. (B) Immunohistochemical staining $(\times 200)$ demonstrated that the tumor cells were positive for H3K27M mutant protein, and the positive site was located in the nucleus. radiotherapy) with a total dose of $45 \mathrm{~Gy}$ were delivered within 5 weeks. After chemoradiotherapy, the muscle strength of right upper limb was improved, and the residual tumor was smaller than before. After an 18-month follow-up, the child's tumor did not progress, and the child's condition was stable and recovered well.

\section{LITERATURE REVIEW}

Pediatric cases of spinal cord DMG with H3 K27M-mutant were retrieved from the Pubmed database. The clinical and radiological profiles were summarized in Table 2.

\section{DISCUSSION}

H3 K27M-mutant DMG is a new type in the fourth revision of WHO classification of central nervous system tumors. This entity represents an invasive midline high-grade glioma differentiated from astrocytes with a histone H3 K27M mutation. It predominantly occurs in the midline structure of the central nervous system, such as the brainstem, thalamus, spinal cord, the third ventricle, hypothalamus, pineal gland, and cerebellum (1-5). H3 K27M-mutant DMGs in pediatric patients are commonly located in the pons, and those arising in the spinal cord are extremely rare. There are few cases reported in the existing literature (6-8). The cervical region is the most frequently involved area of the spinal cord (9).

Its clinical manifestations are non-specific, and they vary according to the involved location of the spinal cord and the tumor growth. Local pain is the most common symptom

\begin{tabular}{|c|c|c|c|c|c|c|c|c|}
\hline 1 & Kumar et al. (2) & $1 / 0$ & 4 & $\begin{array}{l}\text { Cervical thoracic } \\
\text { segment }\end{array}$ & $\begin{array}{l}\text { Progressive } \\
\text { walking difficulty } 3 \\
\text { weeks }\end{array}$ & $\begin{array}{l}\text { There were } \\
\text { abnormally dilated } \\
\text { and irregular areas } \\
\text { of enhancement in } \\
\text { the cervical and } \\
\text { thoracic spinal } \\
\text { cord }\end{array}$ & $\begin{array}{l}\text { Symptomatic } \\
\text { Treatment, } \\
\text { Hormone } \\
\text { Surgeries, Chest } \\
\text { Core Biopsy, } \\
\text { Plasma Exchange }\end{array}$ & $\begin{array}{l}\text { Died within } 4 \\
\text { months of the } \\
\text { diagnosis }\end{array}$ \\
\hline 2 & Okuda et al. (3) & $1 / 0$ & 10 & $\begin{array}{l}\text { Cervical spinal } \\
\text { cord }\end{array}$ & $\begin{array}{l}\text { Progressive } \\
\text { weakness of right } \\
\text { hand }\end{array}$ & $\begin{array}{l}\text { Partial } \\
\text { enhancement of } \\
\text { intramedullary } \\
\text { spinal cord tumor } \\
\text { at C3-7 level }\end{array}$ & $\begin{array}{l}\text { Surgery, } \\
\text { chemoradiation, } \\
\text { targeted therapy }\end{array}$ & Survival \\
\hline
\end{tabular}

NM, Not mentioned. 
that may occur prior to the onset of neurological deficits (10). Common neurological symptoms in children include limb weakness, abnormal gait, and sphincter dysfunctions. In the current case, the girl presented with neck pain and limb weakness, which indicates a possibility of the presence of an intramedullary tumor. It is worth noting that the symptoms in this child progressed rapidly, suggesting that the tumor was highly malignant.

Preoperative diagnosis of spinal cord H3 K27M-mutant DMG is challenging due to the absence of specific MRI characteristics. The tumor appears hypo- to is intensity on T1-weighted imaging and hyperintensity on T2-weighted imaging. Additionally, the boundaries of the tumor are ill-defined, and mild peritumoral edema may be notable. These radiological features are consistent with a high-grade glioma $(4,11,12)$. Some scholars summarized that H3 K27M-mutant DMGs occurring in the cervical spinal cord usually showed uniform enhancement (13). However, in our case, the contrast enhancement of the tumor was heterogeneous, and the peritumoral spinal meninges was also thickened and enhanced. These features are different from those reported in the literature but similar to the radiological characteristics of spinal cord glioblastomas. Differential diagnoses of spinal cord H3 K27M-mutant DMGs should include ependymomas, astrocytomas, and hemangioblastomas.

H3 K27M-mutant DMGs have a broad histomorphological spectrum, varying from WHO Grade II diffuse astrocytomas to WHO Grade IV glioblastomas; in some cases, multiple forms may be concurrent in different tumor areas (14). According to the literature, the $\mathrm{H} 3 \mathrm{~K} 27 \mathrm{M}$ mutation can also be found in oligodendrocytes, giant tumor cells, epithelioid cells, rhabdomyoid tumor cells, primitive neuroectodermal tumor-like areas, pilomyxoid astrocytomas, ependymomas, and pleomorphic xanthoma astrocytomas (5). However, the prognostic relevance of the $\mathrm{H} 3 \mathrm{~K} 27 \mathrm{M}$ mutation remains unclear (15). According to the WHO classification, tumors with the H3 K27M mutation are classified into the Grade IV category, indicating a worse prognosis than the non-mutant counterparts. In our case, the histological morphology conformed to the WHO grade II diffuse astrocytoma.

Immunohistochemically, H3 K27M-mutant DMGs are usually diffusely positive to GFAP, Olig-2, and S-100 proteins. Moreover, p53 is expressed in $~ 50 \%$ of tumors, and expression of ATRX is absent in $15 \%$ of tumors (16-18). In this case, the spinal cord H3 K27M-mutant DMG showed diffuse immunoreactivity to Olig2, GFAP, and S-100, while the expression of ATRX was absent. The Ki-67 index was high, indicating an active proliferation. For tumors of glial origin occurring in the midline of the central nervous system in children, immunohistochemistry should be listed in the routine tests to label the H3 K27M status.

\section{REFERENCES}

1. Louis DN, Perry A, Reifenberger G, von Deimling A, Figarella-Branger D, Cavenee WK, et al. The 2016 World Health Organization classification of tumors of the central nervous system: a summary. Acta Neuropathol. (2016) 131:803-20. doi: 10.1007/s00401-016-1545-1
When necessary, it can be further verified by molecular pathology (e.g., polymerase chain reaction or next-generation sequencing).

To date, there have been no available guidelines for the treatment of H3 K27M-mutant DMGs. Due to the infiltration into the spinal cord parenchyma, complete surgical resection of the tumor is infeasible (19-21). Adjuvant chemoradiotherapy may be helpful for prolonging progression-free survival. In the present case, $\sim 80 \%$ of the tumor volume was removed piece by piece. The child was treated with synchronous radiotherapy and chemotherapy immediately after the surgery. A total of 22 courses of radiotherapy and six cycles of temozolomide were administrated. The disease remained stable after an 18-month follow-up. However, the efficacy of this chemoradiotherapy regimen still needs further validation in a much larger cohort.

In conclusion, we have reported on an extremely rare case of spinal cord H3 K27M-mutant DMG in a pediatric patient. After surgical resection and postoperative concurrent radio- and chemo-therapy, the prognosis is tentatively favorable.

\section{DATA AVAILABILITY STATEMENT}

The original contributions presented in the study are included in the article, further inquiries can be directed to the corresponding author/s.

\section{ETHICS STATEMENT}

The studies involving human participants were reviewed and approved by ethics committee of Beijing Children's Hospital, Capital Medical University, National Center for Children's Health. Written informed consent to participate in this study was provided by the participants' legal guardian/next of kin. Written informed consent was obtained from the individual(s), and minor(s)' legal guardian/next of kin, for the publication of any potentially identifiable images or data included in this article.

\section{AUTHOR CONTRIBUTIONS}

RC and MG conceived the idea, conceptualized the study, and drafted the manuscript. D-PL and DZ collected the data. J-YZ, NZ, and JY analyzed the data. T-TL and JY reviewed the manuscript. All authors read and approved the final draft.

\section{ACKNOWLEDGMENTS}

We would like to acknowledge the hard and dedicated work of all the staff that implemented the intervention and evaluation components of the study.
2. Kumar A, Rashid S, Singh S, Li R, Dure LS. Spinal cord diffuse midline glioma in a 4-year-old boy. Child Neurol Open. (2019) 6:2329048X19842451. doi: 10.1177/2329048X19 842451

3. Okuda T, Hata N, Suzuki SO, Yoshimoto K, Arimura K, Amemiya T, et al. Pediatric ganglioglioma with an $\mathrm{H} 3 \mathrm{~K} 27 \mathrm{M}$ mutation arising from the cervical 
spinal cord. Neuropathology. (2018). doi: 10.1111/neup.12471. [Epub ahead of print].

4. Jung JS, Choi YS, Ahn SS, Yi S, Kim SH, Lee SK. Differentiation between spinal cord diffuse midline glioma with histone H3 K27M mutation and wild type: comparative magnetic resonance imaging. Neuroradiology. (2019) 61:313-22. doi: 10.1007/s00234-019-02154-8

5. Solomon DA, Wood MD, Tihan T, Bollen AW, Gupta N, Phillips JJ, et al. Diffuse Midline gliomas with histone H3-K27M mutation: a series of 47 cases assessing the spectrum of morphologic variation and associated genetic alterations. Brain Pathol. (2016) 26:569-80. doi: 10.1111/bpa.12336

6. Gessi M, Gielen GH, Dreschmann V, Waha A, Pietsch T. High frequency of $\mathrm{H} 3 \mathrm{~F} 3 \mathrm{~A}(\mathrm{~K} 27 \mathrm{M})$ mutations characterizes pediatric and adult highgrade gliomas of the spinal cord. Acta Neuropathol. (2015) 130:4357. doi: $10.1007 / \mathrm{s} 00401-015-1463-7$

7. López G, Oberheim Bush NA, Berger MS, Perry A, Solomon DA. Diffuse non-midline glioma with H3F3A K27M mutation: a prognostic and treatment dilemma. Acta Neuropathol Commun. (2017) 5:38. doi: 10.1186/s40478-017-0440-x

8. Shankar GM, Lelic N, Gill CM, Thorner AR, Van Hummelen P, Wisoff $\mathrm{JH}$, et al. BRAF alteration status and the histone H3F3A gene $\mathrm{K} 27 \mathrm{M}$ mutation segregate spinal cord astrocytoma histology. Acta Neuropathol. (2016) 131:147-150. doi: 10.1007/s00401-015-1492-2

9. Pollack IF. Intramedullary spinal cord astrocytomas in children. Pediatr Blood Cancer. (2004) 43:617-8. doi: 10.1002/pbc.20129

10. De Martino L, Spennato P, Vetrella S, Capasso M, Porfito C, Ruotolo S, et al. Symptomatic malignant spinal cord compression in children: a single-center experience. Ital J Pediatr. (2019) 45:80. doi: 10.1186/s13052-019-0671-5

11. Kim IK, Kim JW, Hwang YJ, Lee BH, Seo JW. Diffuse midline gliomas harboring the $\mathrm{H} 3 \mathrm{~K} 27 \mathrm{M}$-mutation in the bilateral thalamus and midbrain: a case report and a review of the literature. J Korean Soc Radiol. (2017) 77:416-20. doi: 10.3348 /jksr.2017.77.6.416

12. Thust S, Micallef C, Okuchi S, Brandner S, Kumar A, Mankad K, et al. Imaging characteristics of $\mathrm{H} 3 \mathrm{~K} 27 \mathrm{M}$ histone-mutant diffuse midline glioma in teenagers and adults. Quant Imaging Med Surg. (2021) 11:4356. doi: 10.21037/qims-19-954

13. Aboian MS, Solomon DA, Felton E, Mabray MC, Villanueva-Meyer JE, Mueller S, et al. Imaging characteristics of pediatric diffuse midline gliomas with histone H3 K27M mutation. AJNR Am J Neuroradiol. (2017) 38:795800. doi: 10.3174/ajnr.A5076
14. Herrlinger U, Jones DTW, Glas M, Hattingen E, Gramatzki D, Stuplich $\mathrm{M}$, et al. Erratum to: gliomatosis cerebri: no evidence for a separate brain tumor entity. Acta Neuropathol. (2016) 131:321-2. doi: 10.1007/s00401-015$1495-\mathrm{z}$

15. Karremann M, Gielen GH, Hoffmann M, Wiese M, Colditz N, WarmuthMetz M, et al. Diffuse high-grade gliomas with H3 K27M mutations carry a dismal prognosis independent of tumor location. Neuro Oncol. (2018) 20:123-31. doi: 10.1093/neuonc/nox149

16. Komori T. The 2016 WHO classification of tumours of the central nervous system: the major points of revision. Neurol Med Chir. (2017) 57:30111. doi: 10.2176/nmc.ra.2017-0010

17. Wang Y, Feng LL, Ji PG, Liu JH, Guo SC, Zhai YL, et al. Clinical features and molecular markers on diffuse midline gliomas with H3K27M mutations: a 43 cases retrospective cohort study. Front Oncol. (2021) 10:602553. doi: $10.3389 /$ fonc.2020.602553

18. Meyronet D, Esteban-Mader M, Bonnet C, Joly MO, Uro-Coste E, Amiel-Benouaich A, et al. Characteristics of H3 K27M-mutant gliomas in adults. Neuro Oncol. (2017) 19:1127-34. doi: 10.1093/neuonc/ now274

19. Cohen KJ, Broniscer A, Glod J. Pediatric glial tumors. Curr Treat Options Oncol. (2001) 2:529-36. doi: 10.1007/s11864-001-0074-9

20. Castel D, Grill J, Debily MA. Histone H3 genotyping refines clinicoradiological diagnostic and prognostic criteria in DIPG. Acta Neuropathol. (2016) 131:795-6. doi: 10.1007/s00401-016-1568-7

21. Wu G, Broniscer A, McEachron TA, Lu C, Paugh BS, Becksfort J, et al. Somatic histone $\mathrm{H} 3$ alterations in pediatric diffuse intrinsic pontine gliomas and nonbrainstem glioblastomas. Nat Genet. (2012) 44:251-3. doi: 10.1038/ng.1102

Conflict of Interest: The authors declare that the research was conducted in the absence of any commercial or financial relationships that could be construed as a potential conflict of interest.

Copyright (๑) 2021 Cheng, Li, Zhang, Zhang, Zhang, Liu, Yang and Ge. This is an open-access article distributed under the terms of the Creative Commons Attribution License (CC BY). The use, distribution or reproduction in other forums is permitted, provided the original author(s) and the copyright owner(s) are credited and that the original publication in this journal is cited, in accordance with accepted academic practice. No use, distribution or reproduction is permitted which does not comply with these terms. 